\title{
IMPLEMENTASI PEMBELAJARAN BERBASIS MASALAH UNTUK MELATIHKAN KEMAMPUAN BERPIKIR KREATIF DAN PENGUASAAN KONSEP SISWA KELAS V SEKOLAH DASAR
}

\author{
Ahmad Khoirussyifa Amrullah, Muslimin Ibrahim, Wahono Widodo \\ Program Studi S2 Pendidikan Dasar Pascasarjana Universitas Negeri Surabaya \\ email: syifaahmad9061@gmail.com
}

\begin{abstract}
Abstrak
Penelitian ini bertujuan untuk mengetahui bagaimana peningkatan keterampilan berpikir kreatif dan penguasaan konsep siswa sekolah dasar setelah diterapkannya model pembelajaran berbasis masalah. Sampel penelitian ini adalah siswa kelas V di SDN kalirungkut IV Surabaya. Adapun materi yang digunakan dalam penelitian ini adalah materi yang terdapat dalam Tema Lingkunganku Sahabatku Sub Tema manusia dan Lingkungan. Penelitian dilaksanakan pada semester kedua tahun ajaran 2014/2015. Jenis penelitian yang digunakan adalah eksperimen semu yang didahului dengan pengembangan perangkat pembelajaran berbasis masalah. Desain penelitian yang digunakan adalah One Group Pretest Postes Desain. Instrumen yang digunakan dalam penelitian ini meliputi 1) lembar observasi keterlaksanaan pembelajaran; 2) lembar pengamatan aktivitas siswa; 3) instrumen tes penguasaan konsep; dan 4) instrumen tes berpikir kreatif. Adapun teknik analisis menggunakan analisis deskriptif dan untuk mengetahui sejauh mana peningkatan yang dialami peneliti menggunakan analisis N-Gain Skor. Berdasarkan hasil analisis N-gain Skore diperoleh skor N-gain untuk penguasaan konsep siswa tentang materi yang diajarkan adalah 0,67 dengan kategori sedang. Sedangkan dari hasil analisis N-gain skor untuk keterampilan berpikir kreatif yaitu aspek kelancaran 0.59 , aspek keluwesan 0.58 , aspek keaslian 0.59, dan aspek elaborasi 0.58. kategori dari keseluruhan adalah pada level sedang. Kata Kunci: prototipe buku siswa, prototipe buku guru, keterampilan proses sains
\end{abstract}

\section{Abstract}

This study aims to determine how to increase creative thinking skills and mastery of the concept of elementary school students after the implementation of problem-based learning model. The sample was fifth grade students at SDN Kalirungkut IV Surabaya. The material used in this study is the material contained in Themes friends and Sub Themes humans and the environment. The experiment was conducted in the second half of the school year 2014/2015. This type of research is a quasi experiment that begins with the development of problem based learning tools. The study design used is one group pretest posttest design. Intruments was used in this study include1) observation sheet for problem basd learning; 2) observation sheet for student activity; 3) test Instruments for mastery concept; and 4) test instruments for creative thinking skill. Tecnical anaysing using descriptive analysis and to determine the extent of the increase experienced, researcher used $N$-Gain Score analyst.Based on the analysis of $N$-gain score obtained for the N-gain mastery of concepts taught students about the material is 0.67 in the medium category. While the results of the analysis of $\mathrm{N}$-gain scores for creative thinking skills students $\mathrm{N}$-gain Score obtained was 0.59 for fluency aspec, 0.58 for flexibilty aspec, 0.59 for orginality aspec, and 0.58 for elaboration aspec. All of that category is medium level. Keywords: student's book prototype, teacher's book prototype, science process skills

\section{PENDAHULUAN}

Di era modernisasi ini, semakin derasnya arus informasi membuat seseorang harus mempunyai banyak keterampilan untuk mampu bersaing, membuat setiap individu berkesempatan menciptakan ide-ide baru yang belum ada sebelumnya dan dianggap berguna bagi masyarakat. Seperti diketahui, banyak sekali individu mengalami kegagalan dalam bersaing di era modernisasi ini dikarenakan kemampuan berpikir kreatifnya rendah sehingga mudah untuk menyerah ketika terdapat sebuah permasalah. Oleh sebab itu, untuk bersaing pada era modernisasi tersebut, seseorang harus dibekali dengan kemampuan berpikir kreatif mulai sejak dini, khususnya di tingkat sekolah dasar.

Dari data CIA Word Factbook 2004, Indonesia menduduki urutan ke empat untuk jumlah penduduk terbesar di dunia, yaitu sebesar 241.452.952 jiwa orang tinggal di Indonesia, dan jika jumlah warga yang besar tersebut tidak bisa diarahkan potensinya dengan baik, maka jumlah tersebut akan menjadi beban pembangunan bangsa. Oleh karenanya kemampuan berpikir kreatif sudah sepatutnya menjadi salah satu tujuan utama bangsa, dan melalui pendidikanlah tujuan tersebut bisa tercapai.

Pendidikan bertujuan untuk memperbaiki kualitas kehidupan dalam rangkaian pengembangan sumber daya manusia yang bermutu (Hamalik, 1994:10) sejalan dengan pendapat tersebut pengembangan kurikulum menjadi bukti besarnya keinginan pemerintah untuk menjadikan setiap warganya dapat menjadi modal pembangunan. Pentingnya kemampuan berpikir kreatif juga dituangkan secara eksplisit di dalam peraturan 
menteri pendidikan dan kebudayaan Nomor 67 tahun 2013, tentang kerangka dasar dan struktur kurikulum sekolah dasar/madrasah ibtidaiyah, bahwa kurikulum 2013 bertujuan untuk mempersiapkan manusia Indonesia agar memiliki kemampuan hidup sebagai pribadi dan warga negara yang beriman, produktif, kreatif, inovatif, dan afektif serta mampu berkontribusi pada kehidupan bermasyarakat, berbangsa, bernegaa dan peradaban dunia.

Adanya peraturan pemerintah tersebut menandakan bahwasanya berpikir kreatif menjadi salah satu tujuan yang sangat penting utnuk menuju perubahan bangsa. Sejalan dengan hal tesebut Poerwanti (2013:49) menyatakan Kurikulum 2013 memiliki tujuan membentuk perilaku peserta didik, yang digolongkan ke dalam 3 klasifikasi yaitu kognitif, afektif, dan psikomotor. Pendidikan yang baik menuntut adanya pembelajaran yang melatih berbagai keterampilan siswa, salah satu di antaranya adalah keterampilan berpikir kreatif, melalui sebuah kegiatan yang menantang, siswa diharapkan mampu berpikir secara ilmiah yang salah satu di antaranya adalah berpikir secara kreatif. Melalui pembiasaan inilah, diharapkan setiap manusia mempunyai kemampuan untuk berpikir secara kreatif.

Sejalan dengan pengembangan kurikulum, Olson (dalam Hamalik, 2008:64) menyatakan bahwa tujuan pembelajaran ialah mempersiapkan siswa untuk hidup dalam masyarakat. Sekolah semestinya berfungsi menyiapkan siswa untuk menghadapi berbagai masalah dalam kehidupan, mereka bukan dipersiapkan untuk menghadapai masa depan yang masih jauh, 10 atau 20 tahun ke depan, melainkan untuk memecahkan masalahmasalah sehari-hari dalam lingkungannya, di rumah dan di masyarakat. Karena itulah semestinya proses pembelajaran yang baik adalah mengajarkan siswa mengahadapi masalah yang aktual dan terjadi secara langsung.

Kemampuan berpikir kreatif tak akan pernah terwujud jika seseorang belum menguasai konsep suatu hal dengan baik, hal ini seperti yang diungkapkan oleh Gagna (dalam Ibrahim, 2012: 09) bahwa pemahaman konsep adalah kemampuan yang memungkinkan seseorang dapat berbuat sesuatu. Hal ini dapat diartikan bahwa tanpa menguasai konsep tertentu, orang tidak dapat berbuat banyak dan mungkin kelangsungan hidupnya akan terganggu. Pengertian konsep sendiri menurut Ibrahim (2012: 03) didefiniskan sebagai kumpulan stimulus (fakta, benda, peristiwa dll.) yang memiliki ciri yang sama (atribut), sedangkan atribut merupakan ciri esensial yang membedakan contoh konsep dari yang bukan contoh konsep. Dari uraian tersebut melatihkan penguasaan konsep merupakan hal yang penting untuk bisa melatihkan kemampuan berpikir kreatif.

Saat siswa sedang belajar, siswa akan mencoba membentuk suatu konsep tentang hal yang dipejari. Hal ini seperti yang dikemukakan oleh Ibrahim (2011:17) bahwa ketika siswa belajar, sebenarnya mereka melakukan kegiatan merangkai konsep yang telah dimiliki dengan konsep baru, sehingga terjadilah jaring-jaring konsep di dalam benaknya. Salah satu faktor yang menyebabkan sesesorang tidak memahami konsep adalah karena penguasaan konsep seseorang belum lengkap, sederhana dan berbeda. Oleh karenanya butuh suatu pendekatan yang berpusat pada siswa, agar siswa dapat menemukan informasi dari suatu konsep tertentu sehingga informasi yang diperoleh siswa menjadi lebih lengkap, komplek dan sama dengan atribut-atribut konsep pada mestinya.

Kenyataan di lapangan menunjukkan hal yang berbeda. Meskipun SDN Kalirungkut IV/580 Surabaya telah menggunakan kurikulum 2013 yang semestinya guru dituntut lebih inovatif dalam pembelaran, akan tetapi hal itu belum bisa terealisasi dengan baik, berdasarkan pengamatan pada proses pembelajaran yang berlangsung di kelas yang telah menerapkan kurikulum 2013 yaitu kelas 1, 2, 4 dan 5 dengan guru yang berbeda, peneliti mendapatkan beberapa temuan yang menggolongkan pembelajaran di SDN kalirungkut IV/580 Surabaya masih menggunakan satu model pembelajaran untuk beberapa materi yang disampaikan yaitu, 1) guru langsung menyampaikan tujuan pembelajaran, 2) guru kemudian menyajikan informasi tentang materi yang diajarkan, 3) guru meminta anak-anak untuk mengerjakan soal yang ada di buku, 4) guru membahas soal yang telah dikerjakan, dan 5) guru menyimpulkan secara bersama-sama. Cara mengajar seperti yang telah diuraikan kurang efektif untuk melatihkan kemampuan berpikir kreatif siswa. Secara terpisah beberapa penelitian menunjukkan bahwa kurangnya peningkatan kemampuan berpikir kreatif dan kinerja ilmiah yang ditunjukkan oleh siswa. Penelitian yang menunjukkan lemahnya kemampuan berpikir kreatif, antara lain: Rofi'udin (dalam Arnyana, 2007), menemukan bahwa terjadi keluhan tentang 
rendahnya kemampuan berpikir kritis dan kreatif yang dimiliki oleh lulusan pendidikan dasar.

Selain itu dari studi pendahuluan yang dilakukan peneliti di SDN Kalirungkut IV/580 Surabaya, diperoleh data bahwa kemampuan berpikir kreatif siswa masih cukup rendah, hal ini dibuktikan dengan hasil tes kemampuan berpikir kreatif. Dari 38 siswa yang mengikuti tes dengan skala penilaian 1-100 hanya terdapat dua siswa yang masuk dalam kategori berpikir kreatif tinggi dengan interval nilai 75-100, kemudian 5 siswa masuk kategori sedang dengan interval nilai 5074,9 . Sedangkan sisanya sejumlah 31 siswa masuk dalam kategori rendah dengan interval nilai adalah 20-49,9. Bahkan untuk indikator originality dan elaboration siswa rata-rata hanya mendapatkan skor 2 (dengan skala skor 1-5). Ini menunjukkan bahwa ketrampilan untuk memunculkan ide baru dan menjelaskan secara terperinci serta menambahkan suatu detail dirasa masih kurang.

Untuk mengatasi hal tersebut diperlukan tindakan nyata untuk mengurangi faktor-faktor penyebabnya yaitu cara guru mengelola proses belajar mengajar. Untuk melatih keterampilan berpikir kreatif diperlukan sebuah metode yang tepat. Susanto (2012:115) menyatakan bahwa untuk berpikir kreatif perlu diberikan sebuah rangsangan yang berupa masalah. Seseorang akan menjadi kreatif jika menghadapi sebuah masalah. Merujuk dari pendapat tersebut, model yang tepat salah satunya adalah dengan mengimplementasikan pembelajaran berbasis masalah. Borich (2006:69) menyatakan Pembelajaran berbasis masalah merupakan sebuah model pembelajaran yang menggunakan sebuah masalah untuk dianalisis dan kemudian bisa ditentukan solusinya. Pembelajaran berbasis masalah menuntut siswa untuk berpikir lebih kreatif dalam menentukan pemecahan masalah. Sebuah masalah merupakan fasilitas yang menuntut siswa menjadi "pencipta-pencipta kecil" yang akan menyelesaikan masalah dengan disertai sebuah penyelidikan.

Dengan demikian pembelajaran Tidak hanya menerima informasi, pembelajaran berbasis masalah secara tidak langsung akan mengantarkan siswa menjadi pribadi yang kreatif dalam menyelesaikan sebuah masalah dan menentukan sebuah keputusan yang baik. Seorang peserta didik harus diasah keterampilan berpikir kreatif dalam dirinya dengan cara memberikan masalah yang harus dipecahkan menurut pemikirannya sendiri. Hal ini sangat penting dan diperlukan karena pada masa yang akan datang peserta didik akan banyak menghadapi masalah kehidupan yang harus diselesaikan dengan pemikiran yang kreatif.

Berdasarkan uraian di atas, perlu dilakukan perancangan pembelajaran berbasis masalah yang menuntut siswa untuk terlibat lebih aktif dalam kegiatan pembelajaran serta membimbing siswa untuk mengembangkan keterampilan berpikir kreatif dalam menyelesaikan masalah dan menguasai konsep

Tujuan yang ingin dicapai dalam penelitian ini adalah: (1) mendeskripsikan keterlaksanaan Rencana Pelaksanaan Pembelajaran menggunakan model pembelajaran berbasis masalah; (2) mendeskripsikan aktivitas siswa dalam pembelajaran menggunakan model pembelajaran berbasis masalah; (3) mendeskripsikan peningkatan penguasaan konsep siswa setelah diterapkan pembelajaran berbasis masalah.

\section{METODE}

Pada penelitian ini, peneliti menggunakan jenis penelitian pre eksperimen yang didahului dengan pengembangan perangkat. Penelitian pre eksperimen semu digunakan untuk mengetahui bagaimana peningkatan yang terjadi setelah diimplementasikan model PBL terhadap penguasaan konsep dan kemampuan berpikir kreatif siswa. Penelitian ini juga dikategorikan ke dalam penelitian semu karena tanpa adanya pemilihan subjek penelitian secara acak.

Populasi penelitian adalah seluruh siswa kelas adalah siswa kelas 5 SDN Kalirungkut IV Surabaya tahun ajaran 2014/2015. Sampel penelitian sejumlah 30 siswa. Pemilihan SDN Kalirungkut IV Surabaya sebagai tempat penelitian berdasarkan pertimbangan-pertimbangan : (1) sekolah bersifat terbuka dan mau menerima upaya inovasi terhadap pendidikan, (2) kesediaan dari pihak sekolah (kepala sekolah, guru, dan murid) untuk bekerjasama dalam kegiatan penelitian.

Rancangan penelitian yang digunakan adalah One Group Pretest-Posttest Design (Sugiyono, 2013:112) dengan pola sebagai berikut:

\section{$\begin{array}{lll}\mathbf{O}_{1} & \mathbf{X} & \mathbf{O}_{2}\end{array}$}

Peneliti memilih rancangan model tersebut dengan mempertimbangkan beberapa alasan diantaranya : 1) waktu penelitian yang singkat dan terbatas di semester gasal; 2) kelas 5 di SDN Kalirungkut 4 hanya terdiri dari satu kelas; 3) 
mempermudah peneliti dalam mengembangkan perangkat PBL, sehingga perangkat ajar bisa lebih berkualitas. Sementara untuk membantu menyimpulkan bahwa hasil tes merupakan efek pembelajaran yang diterapkan, maka peneliti menggunakan uji sensitivitas butir soal. (Ground dalam Ibrahim, 2005) mengemukakan bahwa uji sensitivitas butir soal digunakan untuk memastikan bahwa hasil tes merupakan efek dari pembelajaran yang diterapkan. Variabel yang diamati dalam penelitian ini adalah : (1) Keterlaksanaan Rencana Pelaksanaan Pembelajaran selama proses pembelajaran dengan menggunakan model pembelajaran berbasis masalah. (2) Aktivitas siswa selama proses pembelajaran menggunakan model pembelajaran berbasis masalah. (3) Penguasaan konsep siswa setelah pelaksanaan pembelajaran menggunakan model pembelajaran berbasis masalah. (4) Kemampuan berpikir kreatif siswa setelah pelaksanaan pembelajaran dengan menggunakan model pembelajaran berbasis masalah.

\section{HASIL DAN PEMBAHASAN}

\section{Spesifikasi Produk Pembelajaran IPS}

Kelas IV Dalam penelitian implementasi Pembelajaran berbasis masalah untuk melatihkan kemampuan berpikir kreatif dan pengusaan konsep siswa sekolah dasar. Setelah butir-butir soal dinyatakan valid oleh validator dan dilakukan revisi sesuai dengan saran yang diberikan oleh validator, soal tes hasil belajar tersebut diuji dianalisis untuk mengetahui tingkat reliabilitas, taraf kesukaran soal serta sensitivitas butir soal. Dari hail uji coba diperoleh hasil sehingga soal tes hasil belajar tersebut layak digunakan sebagai instrumen pengambilan data dalam penelitian.

Butir soal yang sudah dinyatakan valid oleh dosen ahli, selanjutnya diuji tingkat reliabilitasnya. Reliabilitas menunjukkan tingkat keajegan atau keandalan instrumen dalam menjalankan fungsinya sebagai alat ukur. Taraf reliabilitas suatu tes dinyatakan dalam suatu angka koefisien reliabilitas. Berikut hasil perhitungan reliabilitas tes dengan menggunakan program SPSS 16.0 .

Tabel 1. Uji Reliabilitas Soal Tes Penguasaan Konsep

\begin{tabular}{|l|l|}
\hline Cronbach's Alpha & N of Items \\
\hline 0.771 & 25 \\
\hline
\end{tabular}

Dari hasil perhitungan reliabilitas soal tes penguasaan konsep diperoleh nilai $\mathrm{r}$ sebesar = 0,771. Berdasarkan koefisien reliabilitas maka soal tes penguasan konsep yang diuji cobakan tergolong reliabilitas tinggi. Sedangkan untuk taraf reliabilitas soal kemampuan berpikir kreatif dapat dilihat pada Tabel 2.

Tabel 2. Uji Reliabilitas Soal Tes Penguasaan Konsep

\begin{tabular}{|l|l|}
\hline Cronbach's Alpha & N of Items \\
\hline 0.771 & 25 \\
\hline
\end{tabular}

Berdasarkan koefisien reliabilitas maka soal tes kemampuan berpikir kreatif yang diuji cobakan tergolong reliabilitas tinggi.

Taraf kesukaran pada setiap butir soal tes pengusaan konsep dapat dilihat pada tabel 3 .

\begin{tabular}{|c|c|c|c|c|}
\hline $\begin{array}{l}\text { Butir } \\
\text { soal }\end{array}$ & B & J & $\begin{array}{c}\text { Indeks } \\
\text { kesukaran }\end{array}$ & $\begin{array}{c}\text { Taraf } \\
\text { kesukaran }\end{array}$ \\
\hline 1 & 19 & 30 & 0,63 & Mudah \\
\hline 2 & 11 & 30 & 0,37 & Sedang \\
\hline 3 & 10 & 30 & 0,33 & Sedang \\
\hline 4 & 9 & 30 & 0,30 & Sukar \\
\hline 5 & 20 & 30 & 0,67 & Mudah \\
\hline 6 & 24 & 30 & 0,80 & Sedang \\
\hline 7 & 20 & 30 & 0,67 & Mudah \\
\hline 8 & 18 & 30 & 0,60 & Sedang \\
\hline 9 & 12 & 30 & 0,40 & Sedang \\
\hline 10 & 24 & 30 & 0,80 & Mudah \\
\hline 11 & 19 & 30 & 0,63 & Sedang \\
\hline 12 & 17 & 30 & 0,57 & Sedang \\
\hline 13 & 8 & 30 & 0,27 & Sukar \\
\hline 14 & 18 & 30 & 0,60 & Sedang \\
\hline 15 & 19 & 30 & 0,63 & Sedang \\
\hline 16 & 19 & 30 & 0,63 & Sedang \\
\hline 17 & 20 & 30 & 0,67 & Mudah \\
\hline 18 & 9 & 30 & 0,30 & Sukar \\
\hline 19 & 20 & 30 & 0,67 & Sedang \\
\hline 20 & 20 & 30 & 0,67 & Sedang \\
\hline 21 & 5 & 30 & 0,17 & Sukar \\
\hline 22 & 1 & 30 & 0,03 & Sukar \\
\hline 23 & 10 & 30 & 0,33 & Sedang \\
\hline 24 & 17 & 30 & 0,57 & Sukar \\
\hline 25 & 19 & 30 & 0,63 & Sedang \\
\hline \multicolumn{3}{|c|}{ Jumlah } & 12,92 & \\
\hline \multicolumn{3}{|c|}{ Rata-rata } & 0,52 & Sedang \\
\hline
\end{tabular}


Berdasarkan Tabel.3. Dapat dilihat bahwa rata-rata taraf kesukaran soal tes kemampuan penguasaan konsep adalah 0,52. Berdasarkan koefisien taraf kesukaran soal, secara keseluruhan butir soal penguasaan konsep masuk dalam kategori sedang sehingga soal tes kemampuan penguasaan konsep siswa bisa digunakan untuk mengukur penguasaan konsep siswa pada uji sesungguhnya.

Setiap butir soal pada intrumen tes penguasaan konsep juga dilihat sensitivitas atau kepekaan dalam mengukur hasil pembelajaran menggunakan model PBL. Sensitivitas butir soal dianalisa dari jumlah siswa yang menjawab benar pada post tes dibagi dengan jumlah siswa yang menjawab benar pada pre test. Sensistivitas butir soal tes penguasaan konsep dapat dilihat pada tabel 4

Tabel 4. Uji Sensitivitas Butir Soa

\begin{tabular}{|c|c|c|c|c|}
\hline Butir soal & $\mathrm{R}_{\mathrm{a}}$ & $R_{b}$ & $\begin{array}{c}\text { Indeks } \\
\text { sensitivitas }\end{array}$ & Kriteria \\
\hline 1 & 1 & 29 & 19 & $\mathrm{~S}$ \\
\hline 2 & 2 & 26 & 11 & $\mathrm{~S}$ \\
\hline 3 & 3 & 30 & 10 & $S$ \\
\hline 4 & 4 & 28 & 9 & $S$ \\
\hline 5 & 5 & 30 & 20 & $\mathrm{~S}$ \\
\hline 6 & 6 & 30 & 24 & TS \\
\hline 7 & 7 & 30 & 20 & $\mathrm{~S}$ \\
\hline 8 & 8 & 28 & 18 & $\mathrm{~S}$ \\
\hline 9 & 9 & 26 & 12 & $\mathrm{~S}$ \\
\hline 10 & 10 & 30 & 24 & TS \\
\hline 11 & 11 & 26 & 19 & TS \\
\hline 12 & 12 & 27 & 17 & $\mathrm{~S}$ \\
\hline 13 & 13 & 24 & 8 & $\mathrm{~S}$ \\
\hline 14 & 14 & 28 & 18 & $\mathrm{~S}$ \\
\hline 15 & 15 & 29 & 19 & $\mathrm{~S}$ \\
\hline 16 & 16 & 30 & 19 & $\mathrm{~S}$ \\
\hline 17 & 17 & 29 & 20 & $S$ \\
\hline 18 & 18 & 29 & 9 & $\mathrm{~S}$ \\
\hline 19 & 19 & 29 & 20 & $\mathrm{~S}$ \\
\hline 20 & 20 & 30 & 20 & $S$ \\
\hline 21 & 21 & 28 & 5 & $S$ \\
\hline 22 & 22 & 22 & 1 & $\mathrm{~S}$ \\
\hline 23 & 23 & 22 & 10 & $\mathrm{~S}$ \\
\hline 24 & 24 & 27 & 17 & $\mathrm{~S}$ \\
\hline 25 & 25 & 29 & 19 & $S$ \\
\hline \multicolumn{3}{|c|}{ Jumlah } & 10.27 & \\
\hline \multicolumn{3}{|c|}{ Rata-fata } & 0,41 & Sensitif \\
\hline
\end{tabular}

Berdasarkan $\quad$ Tabel 4 tersebut memperlihatkan bahwa terdapat 22 butir soal yang tergolong sensitiv dan 3 soal yang tergolong tidak sensitiv. Secara keseluruhan rata-rata sensitivitas setiap butir soal adalah 0,41 sehingga secara keseluruhan soal-soal tes penguasaan tergolong sensitif. Dari hal tersebut dapat disimpulkan bahwa hasil tes merupakan efek dari pembelajaran.

Semua fase dalam rencana pelaksanaan pembelajaran model PBL telah terlaksana dengan presentase keterlaksanaan adalah 93,75\%. Adapun kategori keterlaksanaan adalah baik sekali. Pada pembelajaran dua dengan menggunakan model PBL dua pengamat memberikan penilaian.

Keterlaksanaan pembelajaran 2 menggunakan PBL bahwa semua fase dalam rencana pelaksanaan pembelajaran model PBL telah terlaksana dengan presentase keterlaksanaan adalah 91,67 \%. Adapun kategori keterlaksanaan adalah baik sekali.

Hasil pengamatan aktivitas siswa pada pembelajaran 1 menggunakan model PBL yang dilakukan oleh dua orang pengamat Memperlihatkan bahwa $70 \%$ siswa telah melakukan aktivitas sesuai dengan kegiatan yang direncanakan meskipun masih terdapat beberapa aktivitas yang kurang relevan dalam pembelajaran, seperti ketika berdiskusi terdapat siswa yang asik bergurau dengan salah satu teman atau tidak turut serta dalam kegiatan. Meskipun demikian persentase aktivitas siswa menunjukan bahwa aktivitas berjalan dengan baik dan berjalan dengan tahap-tahap yang direncanakan dalam RPP.

Pada pembelajaran ke dua dengan menerapkan model PBL, hasil pengamatan yang dilakukan oleh dua orang pengamat memperlihatkan bahwa $73 \%$ siswa telah melakukan aktivitas sesuai dengan rencana pelaksanaan pembelajaran 2 dengan menerapkan model PBL. Hasil tes penguasaan konsep siswa kelompok eksperimen bisa dilihat pada Tabel 5

Tabel 5. Skor Tes Pengusaan Konsep Sisswa

\begin{tabular}{|c|c|c|c|c|}
\hline No & $\begin{array}{c}\text { skor } \\
\text { pre tes }\end{array}$ & Kategori & $\begin{array}{c}\text { skor } \\
\text { pos tes }\end{array}$ & Kategori \\
\hline 1 & 45 & TT & 80 & T \\
\hline 2 & 48 & TT & 77 & T \\
\hline 3 & 40 & TT & 75 & T \\
\hline 4 & 35 & TT & 83 & T \\
\hline 5 & 57 & TT & 75 & T \\
\hline 6 & 35 & TT & 80 & T \\
\hline 7 & 80 & T & 100 & T \\
\hline
\end{tabular}




\begin{tabular}{|c|c|c|c|c|}
\hline 8 & 67 & TT & 97 & T \\
\hline 9 & 67 & TT & 100 & T \\
\hline 10 & 35 & TT & 85 & T \\
\hline 11 & 40 & TT & 83 & T \\
\hline 12 & 60 & TT & 93 & T \\
\hline 13 & 40 & TT & 85 & T \\
\hline 14 & 68 & TT & 93 & T \\
\hline 15 & 72 & T & 87 & T \\
\hline 16 & 93 & T & 100 & T \\
\hline 17 & 67 & TT & 97 & T \\
\hline 18 & 62 & TT & 97 & T \\
\hline 19 & 67 & TT & 100 & T \\
\hline 20 & 50 & TT & 85 & T \\
\hline 21 & 72 & T & 85 & T \\
\hline 22 & 57 & TT & 85 & T \\
\hline 23 & 52 & TT & 87 & T \\
\hline 24 & 67 & TT & 95 & T \\
\hline 25 & 62 & TT & 92 & T \\
\hline 26 & 70 & TT & 100 & T \\
\hline 27 & 62 & TT & 87 & T \\
\hline 28 & 42 & TT & 87 & T \\
\hline 29 & 57 & TT & 100 & T \\
\hline 30 & 67 & TT & 95 & T \\
\hline Jumlah & 1736 & & 2685 & \\
\hline $\begin{array}{c}\text { Rata- } \\
\text { rata }\end{array}$ & 57,87 & TT & 89,50 & T \\
\hline
\end{tabular}

Berdasarkan Tabel 5. Memperlihatkan bahwa skor rata-rata pre test adalah 57,87 dengan kategori rata-rata adalah tidak tuntas. Sedangkan hasil post test memeperlihatkan bahwa skor ratarata kelompok eksperimen adalah 89,50 dengan kriteria tuntas.

Untuk mengetahui pengaruh pembelajaran terhadap Penguasaan Konsep, dilakukan analisis deskriptif kualitatif berupa analisis N-Gain Score. Gain menunjukkan perbedaan penguasaan konsep siswa sebelum serta setelah diberikan perlakuan. Hasil analisis N-Gain Score penguasaaan konsep siswa setelah diberi perlakuan menggunakan model PBL disajikan ke dalam Tabel 6.

Tabel 6. Analisis N-Gain Penguasaan Konsep Siswa

\begin{tabular}{|c|c|c|c|c|}
\hline Siswa & $\begin{array}{l}\text { Pre } \\
\text { Test }\end{array}$ & $\begin{array}{l}\text { Post } \\
\text { test }\end{array}$ & $\mathrm{N}$-gain & Kategori \\
\hline 1 & 45 & 80 & 0,64 & $\mathrm{~S}$ \\
\hline 2 & 48 & 77 & 0,56 & $\mathrm{~S}$ \\
\hline 3 & 40 & 75 & 0,58 & $\mathrm{~S}$ \\
\hline 4 & 35 & 83 & 0,74 & $\mathrm{~T}$ \\
\hline 5 & 57 & 75 & 0,42 & $\mathrm{~S}$ \\
\hline 6 & 35 & 80 & 0,69 & $\mathrm{~S}$ \\
\hline 7 & 80 & 100 & 0,65 & $\mathrm{~S}$ \\
\hline 8 & 67 & 97 & 0,91 & $\mathrm{~T}$ \\
\hline 9 & 67 & 100 & 0,79 & $\mathrm{~S}$ \\
\hline 10 & 35 & 85 & 0,77 & $\mathrm{~S}$ \\
\hline 11 & 40 & 83 & 0,72 & $\mathrm{~S}$ \\
\hline 12 & 60 & 93 & 0,83 & $\mathrm{~S}$ \\
\hline 13 & 40 & 85 & 0,75 & $\mathrm{~S}$ \\
\hline 14 & 68 & 93 & 0,59 & $\mathrm{~S}$ \\
\hline 15 & 72 & 87 & 0,54 & $\mathrm{~S}$ \\
\hline 16 & 93 & 100 & 0,00 & $\mathrm{~S}$ \\
\hline 17 & 67 & 97 & 0,70 & $\mathrm{~S}$ \\
\hline 18 & 62 & 97 & 0,74 & $\mathrm{~S}$ \\
\hline 19 & 67 & 100 & 0,85 & $\mathrm{~S}$ \\
\hline 20 & 50 & 85 & 0,60 & $\mathrm{~S}$ \\
\hline 21 & 72 & 85 & 0,29 & $\mathrm{~S}$ \\
\hline 22 & 57 & 85 & 0,65 & $\mathrm{~S}$ \\
\hline 23 & 52 & 87 & 0,73 & $\mathrm{~T}$ \\
\hline 24 & 67 & 95 & 0,85 & $\mathrm{~T}$ \\
\hline 25 & 62 & 92 & 0,79 & $\mathrm{~T}$ \\
\hline 26 & 70 & 100 & 0,83 & $\mathrm{~T}$ \\
\hline 27 & 62 & 87 & 0,47 & $\mathrm{~S}$ \\
\hline 28 & 42 & 87 & 0,78 & $\mathrm{~T}$ \\
\hline 29 & 57 & 100 & 0,88 & $\mathrm{~T}$ \\
\hline 30 & 67 & 95 & 0,85 & $\mathrm{~T}$ \\
\hline \multicolumn{3}{|c|}{ Jumlah } & 20,17 & \\
\hline \multicolumn{3}{|c|}{ Rata-rata N-Gain } & 0,67 & $\mathrm{~S}$ \\
\hline
\end{tabular}

Keterangan

$\mathrm{S}=$ sedang

$\mathrm{T}=$ tinggi

Berdasarkan Tabel 4.10 menunjukkan bahwa terdapat 20 siswa dengan kategori $\mathrm{N}$-gain sedang, dan terdapat 10 siswa dengan kategori $\mathrm{N}$ Gain tinggi. Secara kesuluruhan $\mathrm{N}$-gain score kelompok mendapatkan rata-rata $\mathrm{N}$-gain score 0,67. Berdasarkan koefisien $\mathrm{N}$-gain score maka rata-rata $\mathrm{N}$-Gain score kelompok eksperimen tergolong 
sedang. Hal tersebut menunjukkan terdapat peningkatan pada penguasaan konsep siswa terhadap materi yang terdapat dalam tema lingkunganku sahabatku dan sub tema manusia dan lingkungan.

Hasil tes kemampuan berpikir kreatif siswa setelah diterapkan model pembelajaran berbasis masalah disajikan secara terpisah berdasarkan aspek-aspek berpikir kreatif. Hal tersebut disebabkan setiap aspek mempunyai tingkat kesulitan tersendiri sehingga nilai dari tiap aspek tidak disamaratakan..

Dibawah ini disajikan tabel hasil tes keterampilan berpikir kreatif aspek Fluency (kelancaran) serta analisis N-Gain terhadap hasil tes.

Tabel 7. Hasil Tes Keterampilan Berpikir Kreatif Aspek Fluency Dan Analisis N-Gain Aspek Fluency

\begin{tabular}{|c|c|c|c|c|}
\hline No Siswa & $\begin{array}{l}\text { Skor Pre } \\
\text { Tes }\end{array}$ & $\begin{array}{l}\text { Skor Pos } \\
\text { Tes }\end{array}$ & $\mathrm{N}$-Gain & $\begin{array}{l}\text { Kategori } \\
\text { Peningkatan }\end{array}$ \\
\hline 1 & 3 & 4 & 0,50 & $S$ \\
\hline 2 & 1 & 3 & 0,50 & $\mathrm{~T}$ \\
\hline 3 & 1 & 4 & 0,75 & $\mathrm{~T}$ \\
\hline 4 & 1 & 4 & 0,75 & $\mathrm{~T}$ \\
\hline 5 & 1 & 3 & 0,50 & $\mathrm{~S}$ \\
\hline 6 & 1 & 3 & 0,50 & $\mathrm{~S}$ \\
\hline 7 & 4 & 5 & 1,00 & $\mathrm{~T}$ \\
\hline 8 & 4 & 5 & 1,00 & $\mathrm{~T}$ \\
\hline 9 & 1 & 5 & 1,00 & $\mathrm{~T}$ \\
\hline 10 & 1 & 4 & 0,75 & $\mathrm{~T}$ \\
\hline 11 & 1 & 4 & 0,75 & $\mathrm{~T}$ \\
\hline 12 & 1 & 4 & 0,75 & $\mathrm{~T}$ \\
\hline 13 & 1 & 4 & 0,75 & $\mathrm{~T}$ \\
\hline 14 & 3 & 3 & 0,00 & $\mathrm{R}$ \\
\hline 15 & 3 & 4 & 0,50 & $\mathrm{~S}$ \\
\hline 16 & 4 & 5 & 1,00 & $\mathrm{~T}$ \\
\hline 17 & 4 & 4 & 0,00 & $R$ \\
\hline 18 & 1 & 4 & 0,75 & $\mathrm{~T}$ \\
\hline 19 & 4 & 5 & 1,00 & $\mathrm{~T}$ \\
\hline 20 & 4 & 5 & 1,00 & $\mathrm{~T}$ \\
\hline 21 & 2 & 4 & 0,67 & $\mathrm{~S}$ \\
\hline 22 & 3 & 5 & 1,00 & $\mathrm{~T}$ \\
\hline 23 & 3 & 4 & 0,50 & $\mathrm{~s}$ \\
\hline 24 & 2 & 3 & 0,33 & $\mathrm{~S}$ \\
\hline 25 & 1 & 3 & 0,50 & $\mathrm{~S}$ \\
\hline 26 & 2 & 3 & 0,33 & $\mathrm{~S}$ \\
\hline 27 & 4 & 4 & 0,00 & $\mathrm{R}$ \\
\hline 28 & 3 & 4 & 0,50 & $\mathrm{~S}$ \\
\hline 29 & 2 & 5 & 1,00 & $\mathrm{~T}$ \\
\hline 30 & 2 & 3 & 0,33 & $\mathrm{~S}$ \\
\hline $\begin{array}{l}\text { Jumla } \\
\mathrm{h}\end{array}$ & 68 & 120 & 18,92 & \\
\hline $\begin{array}{l}\text { Rata- } \\
\text { rata }\end{array}$ & 2,27 & 4,00 & 0,63 & $\mathrm{~S}$ \\
\hline
\end{tabular}

Berdasarkan Tabel 7. hasil pre test kemampuan berpikir kreatif pada aspek Fluency (kelancaran) memperlihatkan skor rata-rata pre tes aspek tersebut adalah 2,27. Berdasarkan koefisien skor yang tertera di rubrik penilaian ( lihat lampiran rubrik penilaian berpikir kreatif) maka dapat diartikan rata-rata siswa hanya dapat menuliskan 3 pertanyaan yang sesuai dengan kasus penumpukan sampah. Sedangkan rata-rata pos tes adalah 4,00. Dan berdasarkan analisis N-Gain terhadap hasil skor aspek flunecy (kelancaran) menunjukkan peningkatan yang positif yaitu 0,59 dengan kategori sedang. Hal ini menunjukkan peningkatan yang lebih baik dalam aspek kelancaran setelah pembelajaran PBL diterapkan.

Tabel 8. Hasil Tes Keterampilan Berpikir Kreatif Aspek Flexibity Dan Analisis N-Gain Aspek Flexibilty

\begin{tabular}{|c|c|c|c|c|}
\hline $\begin{array}{l}\text { No } \\
\text { Siswa }\end{array}$ & $\begin{array}{l}\text { Skor } \\
\text { Pre Tes }\end{array}$ & $\begin{array}{l}\text { Skor Pos } \\
\text { Tes }\end{array}$ & $\mathrm{N}-$ Gain & $\begin{array}{l}\text { Kategori } \\
\text { Peningkatan }\end{array}$ \\
\hline 1 & 1 & 2 & 0,25 & $\mathrm{R}$ \\
\hline 2 & 1 & 3 & 0,50 & $\mathrm{~S}$ \\
\hline 3 & 2 & 2 & 0,00 & $\mathrm{R}$ \\
\hline 4 & 1 & 3 & 0,50 & $\mathrm{~S}$ \\
\hline 5 & 2 & 3 & 0,33 & $\mathrm{~S}$ \\
\hline 6 & 1 & 3 & 0,50 & $\mathrm{~S}$ \\
\hline 7 & 3 & 5 & 1,00 & $\mathrm{~T}$ \\
\hline 8 & 1 & 4 & 0,75 & $\mathrm{~T}$ \\
\hline 9 & 3 & 5 & 1,00 & $\mathrm{~T}$ \\
\hline 10 & 1 & 3 & 0,50 & $\mathrm{~S}$ \\
\hline 11 & 1 & 3 & 0,50 & $\mathrm{~S}$ \\
\hline 12 & 1 & 4 & 0,75 & $T$ \\
\hline 13 & 1 & 3 & 0,50 & $\mathrm{~S}$ \\
\hline 14 & 1 & 5 & 1,00 & $\mathrm{~T}$ \\
\hline 15 & 2 & 3 & 0,33 & $\mathrm{~S}$ \\
\hline 16 & 4 & 5 & 1,00 & $\mathrm{~T}$ \\
\hline 17 & 3 & 5 & 1,00 & $\mathrm{~T}$ \\
\hline 18 & 1 & 5 & 1,00 & $\mathrm{~T}$ \\
\hline 19 & 4 & 5 & 1,00 & $\mathrm{~T}$ \\
\hline 20 & 2 & 3 & 0,33 & $\mathrm{~S}$ \\
\hline 21 & 3 & 4 & 0,50 & $\mathrm{~S}$ \\
\hline 22 & 3 & 3 & 0,00 & $R$ \\
\hline 23 & 3 & 4 & 0,50 & $\mathrm{~S}$ \\
\hline 24 & 1 & 2 & 0,25 & $\mathrm{R}$ \\
\hline 25 & 1 & 3 & 0,50 & $\mathrm{~S}$ \\
\hline 26 & 3 & 4 & 0,50 & $\mathrm{~S}$ \\
\hline 27 & 2 & 4 & 0,67 & $\mathrm{~S}$ \\
\hline 28 & 2 & 4 & 0,67 & $S$ \\
\hline 29 & 2 & 4 & 0,67 & $\mathrm{~S}$ \\
\hline 30 & 1 & 3 & 0,50 & $\mathrm{~S}$ \\
\hline lah & 57 & 109 & 17,50 & \\
\hline $\begin{array}{c}\text { Rat } \\
\text { a-rata }\end{array}$ & $\begin{array}{ll} & 1,9 \\
0 & \end{array}$ & 3,63 & 0,58 & S \\
\hline
\end{tabular}


Berdasarkan Tabel 8. Hasil skor tes dan analisis N-Gain pada aspek flexibilty (keluwesan) memperlihatkan skor rata-rata pre tes aspek tersebut adalah 1,90. Berdasarkan koefisien skor yang tertera di rubrik penilaian maka dapat diartikan bahwa rata-rata siswa hanya dapat memberikan tanggapan dengan satu sudut pandang terhadap msalah yang diberikan. Sedangkan rata-rata pos tes adalah 3,63. Dan berdasarkan analisis N-Gain terhadap hasil skor aspek flexibilty (keluwesan) menunjukkan peningkatan yang positif yaitu 0,58 dengan kategori sedang. Hal ini menunjukkan peningkatan yang lebih baik dalam aspek keluwesan setelah pembelajaran PBL diterapkan.

Hasil skor tes dan analisis N-Gain pada aspek originality ( keaslian ) disajikan pada tabel 8 . berikut.

\begin{tabular}{|c|c|c|c|c|}
\hline $\begin{array}{c}\text { No } \\
\text { Siswa }\end{array}$ & $\begin{array}{c}\text { Skor } \\
\text { Pre Tes }\end{array}$ & $\begin{array}{c}\text { Skor } \\
\text { Pos Tes }\end{array}$ & N-Gain & $\begin{array}{c}\text { Kategori } \\
\text { Peningkatan }\end{array}$ \\
\hline 1 & 1 & 3 & 0,50 & $\mathrm{~S}$ \\
\hline 2 & 2 & 3 & 0,33 & $\mathrm{~S}$ \\
\hline 3 & 1 & 4 & 0,75 & $\mathrm{~T}$ \\
\hline 4 & 1 & 4 & 0,75 & $\mathrm{~T}$ \\
\hline 5 & 2 & 2 & 0,00 & $\bar{R}$ \\
\hline 6 & 1 & 3 & 0,50 & $\mathrm{~S}$ \\
\hline 7 & 2 & 5 & 1,00 & $\mathrm{~T}$ \\
\hline 8 & 3 & 5 & 1,00 & $\mathrm{~T}$ \\
\hline 9 & 3 & 4 & 0,50 & $\mathrm{~S}$ \\
\hline 10 & 2 & 3 & 0,33 & $\mathrm{~S}$ \\
\hline 11 & 2 & 3 & 0,33 & $S$ \\
\hline 12 & 1 & 4 & 0,75 & $\mathrm{~T}$ \\
\hline 13 & 2 & 4 & 0,67 & $S$ \\
\hline 14 & 2 & 5 & 1,00 & $\mathrm{~T}$ \\
\hline 15 & 3 & 4 & 0,50 & $\mathrm{~S}$ \\
\hline 16 & 1 & 4 & 0,75 & $\mathrm{~T}$ \\
\hline 17 & 1 & 4 & 0,75 & $\mathrm{~T}$ \\
\hline 18 & 1 & 4 & 0,75 & $\mathrm{~T}$ \\
\hline 19 & 4 & 4 & 0,00 & $\mathrm{R}$ \\
\hline 20 & 2 & 4 & 0,67 & $S$ \\
\hline 21 & 3 & 5 & 1,00 & $\mathrm{~T}$ \\
\hline 22 & 2 & 3 & 0,33 & $\mathrm{~S}$ \\
\hline 23 & 1 & 5 & 1,00 & $\mathrm{~T}$ \\
\hline 24 & 2 & 3 & 0,33 & $\mathrm{~S}$ \\
\hline 25 & 1 & 3 & 0,50 & $\mathrm{~S}$ \\
\hline 26 & 2 & 4 & 0,67 & $\mathrm{~S}$ \\
\hline 27 & 2 & 3 & 0,33 & $\mathrm{~S}$ \\
\hline 28 & 1 & 4 & 0,75 & $\mathrm{~T}$ \\
\hline 29 & 1 & 5 & 1,00 & $\mathrm{~T}$ \\
\hline 30 & 3 & 3 & 0,00 & $R$ \\
\hline Jumlah & 55,00 & 114,00 & 17,75 & \\
\hline $\begin{array}{c}\text { Rata- } \\
\text { rata }\end{array}$ & 1,83 & 3,80 & 0,59 & S \\
\hline
\end{tabular}

Berdasarkan Tabel 9 hasil pre test kemampuan berpikir kreatif pada aspek originality (keaslian) memperlihatkan skor rata-rata pre tes aspek tersebut adalah 1,83. Berdasarkan koefisien skor yang tertera di rubrik penilaian ( lihat lampiran rubrik penilaian berpikir kreatif) maka dapat diartikan bahwa rata-rata siswa kurang mampu mencetuskan ide alternatif. Sedangkan rata-rata pos tes adalah 3,80. Dan berdasarkan analisis N-Gain terhadap hasil skor aspek originality (keaslian) menunjukkan peningkatan yang positif yaitu 0,59 dengan kategori sedang.

Hasil skor tes dan analisis N-Gain pada aspek elaboration (mengembangkan gagasan) memperlihatkan skor rata-rata pre tes aspek tersebut adalah 1,17. Berdasarkan koefisien skor yang tertera di rubrik penilaian ( lihat lampiran rubrik penilaian berpikir kreatif) maka dapat diartikan bahwa rata-rata siswa hanya mampu mengembangkan kalimat di dalam tugas kurang dari dua paragrap. Sedangkan rata-rata pos tes adalah 3,40. Hal ini dapat diartikan bahwa setelah diterapkan PBL rata-rata siswa dapat mengembangkan kalimat yang diberikan menjadi 3 sampai 4 paragraph meskipun kalimat yang dikembangkan kurang runtut. Dan berdasarkan analisis N-Gain terhadap hasil skor aspek elaboration (mengembangkan gagasan, menambahkan detail) menunjukkan peningkatan yang positif yaitu 0,58 dengan kategori sedang. Hal ini menunjukkan peningkatan yang lebih baik dalam aspek kelancaran setelah pembelajaran PBL diterapkan.

\section{PENUTUP}

Berdasarkan pembahasan hasil penelitian dapat ditarik kesimpulan sebagai berikut; 1) Pembelajaran di kelas $\mathrm{V}$ tema lingkunganku sahabatku sub tema manusia dan lingkungan menggunakan model pembelajaran PBL terlaksana dengan baik ; 2) Aktivitas siswa kelas V pada pembelajaran tema lingkunganku sahabatku sub tema manusia dan lingkungan menggunakan model PBL sesuai dengan fase pembelajaran PBL; 3) Penguasaan konsep siswa kelas V terhadap materi yang terdapat dalam Tema Lingkungaku Sahabatku Sub Tema Manusia dan Lingkungan meningkat setelah diajarkan dengan menggunakan model PBL; 4) Kemampuan berpikir kreatif siswa kelas V meningkat setelah diajarkan dengan menggunakan model PBL 


\section{DAFTAR PUSTAKA}

Arifin, Zainal. 2011. Penelitian Pendidikan. Bandung: PT Remaja Rosdakarya.

Arikunto, Suharsimi. 1989. Manajemen Penelitian. Jakarta: Departemen Pendidikan dan Kebudayaan.

Azwar, Saifuddin. 2012. Tes Prestasi. Yogyakarta: Pustaka Pelajar.

Bilgin, 2009. The Effect of Problem Based Learning Instruction on University Student' Performance of Conceptual and Quantitative Problem in Gas Concept. Turki : Eurasia Journal of Mathematics, Science and Technology Education.

Borich, Garry. 2006. Teaching Strategi That Promote Thinking. Singapore: McGrawHill.

Deporter, Bobby. 2011. Quantum Learning. Bandung: Mizan Pustaka.

Eldy, Sulaiman. 2013. The Role of PBL in Improving Physics Student' Creative Thinking and Its Imprint on Gender. Sabah. International Journal of Education and Research.

Filsaime, Dennis K. 2008. Menguak Rahasia Berpikir Kritis dan Kreatif. Jakarta: Prestasi Pustaka Publisher

Fogarty, Robin. 1991. How to Integrated The Curricula. Illinois: IRI/Skylight Publishing, Inc.

Hamalik, Oemar. 2008. Kurikulum dan Pembelajaran. Jakarta: Sinar Grafika

Ibrahim, Muslimin. 2012. Konsep, Miskonsepsi, dan Cara Pembelajarannya. Surabaya, Unesa University Press.

Ibrahim, Muslimin. 2005. Assesment Berkelanjutan. Surabaya, Unesa University Press.

Julianto,dkk. 2011. Teori Implikasi Model-Model Pembelajaran Inovatif. Surabaya: Unesa Press.
Kemp, Jerrold E. 1994. Designing Effective Instuction. New York: Macmillan College Publishing Compagny.

Khoiri. 2013. Implementasi Model Problem Based Learning Berbantuan Multimedia Untuk Meningkatkan Kemampuan Berpikir Kreatif Siswa Kelas VII SMP Negeri 4 Kudus Pada Materi Segitiga. Skripsi, Unnes

Lau, Joe. 2011. An Introduction To Critical Thingking And Creativity Thingking. New Jersey : John willey \& Son,Inc.

Nur, Muhammad. 2011. Pembelajaran Bebasis Masalah. Surabaya: Unesa Press

Nur, Muhammad. 2008. Pengajaran Berpusat Pada Siswa Dan Pendekatan Kontruktifis Dalam Pengajaran. Surabaya: Unesa Press

Poerwati, Endah. 2013. Panduan Memahami Kurikulum 2013. Jakarta: Prestasi Pustaka

Pratiwi, 2010. Pembelajaran Berbasis Masalah (Problem Based Learning) Dengan Metode Proyek Dan Resitasiditinjau Dari Kreativitas Dan Konsep Diri (Self Concept) Siswa. Tesis magister pendidikan, Universitas Sebelasa Maret.

Ramli, Awang. 2008. Creative Thinking Skill Approach Through Problem-Based Learning: Pedagogy and Practice in the Engineering Classroom. Kuala Lumpur: International Journal of Social, Management, Economics and Business Engineering

Siswono ,dkk. 2014. Pengaruh Problem Based Learning Berbantuan Virtual Laboratory Terhadap Ketrampilan Proses Sains Dan Penguasaan Konsep Siswa Di SMA. Tesis Magister Pendidikan, Universitas Negeri Malang.

Sudarma, Momon. 2013. Mengembangkan Keterampilan Berpikir Kreatif. Jakarta: Raja Grafindo Persada 
Sugiyono. 2013. Metode Penelitian Pendidikan.

Bandung: Alfabeta.

Susanto, Ahmad. 2012. Teori Belajar dan Pembelajaran di Sekolah Dasar. Jakarta: Prenada Media Group.

Taniredja, Tukiran. 2011. Penelitian Kuantitatif (Sebuah Pengantar). Bandung: Alfabeta. 